\title{
Relationship between physical strain during standardised ADL tasks and physical capacity in men with spinal cord injuries
}

\author{
T W J Janssen PhD, C A J M van Oers MSc PT, H E J Veeger PhD, A P Hollander
} $\mathrm{PhD}, \mathrm{L} \mathrm{H}$ V van der Woude $\mathrm{PhD}, \mathrm{R} \mathrm{H}$ Rozendal $\mathrm{PhD}$

\begin{abstract}
Faculty of Human Movement Sciences, Department of Exercise Physiology and Biophysics, Vrije Universiteit, Van der Boechorststraat 9, 1081 BT Amsterdam, The Netherlands.
\end{abstract}

To describe physical strain during activities of daily living (ADL), 44 men with spinal cord injuries (C4-L5) performed a set of standardised tasks. The physical strain was defined as the highest heart rate response expressed as a percentage of the individual heart rate reserve (\%HRR). The physical strain averaged over the subjects who performed all tasks $(n=24)$ was (mean $\pm \mathrm{SD})$ : $20.2 \pm 7.2 \% \mathrm{HRR}$ (washing hands), $20.4 \pm 7.3 \% \mathrm{HRR}$ (passing a side-hung door), $28.8 \pm 10.8 \%$ HRR (transfer to a toilet), $31.2 \pm 13.1 \% \mathrm{HRR}$ (ascending an $8 \mathrm{~cm}$ curb), $33.9 \pm 12.0 \% \mathrm{HRR}$ (transfer to a shower seat), $35.1 \pm 10.5 \%$ HRR (transfer to bed), $36.4 \pm 13.3 \%$ HRR (preparing lunch), $37.1 \pm 12.0 \%$ HRR (washing up), $38.7 \pm 14.9 \%$ HRR (ascending a ramp), $39.8 \pm 15.6 \%$ HRR (transfer to a shower wheelchair), $41.4 \pm 12.1 \%$ HRR (changing sheets), and $45.9 \pm 10.4 \% \mathrm{HRR}$ (entering a car). Physical strain could be notably high, but large variations among subjects were present. During all tasks, subjects with tetraplegia had significantly higher levels of strain than subjects with low (T6-L5) lesions. Physical strain was inversely related to parameters of physical capacity: isometric strength ( $\mathrm{r}$ : -0.34 to -0.72$)$, sprint power ( $\mathrm{r}$ : -0.34 to -0.69$)$, peak oxygen uptake $(r$ : -0.41 to -0.81$)$ and maximal power output $(r:-0.52$ to -0.82$)$. Parameters of physical capacity were better predictors of physical strain than was the lesion level, and explained $37-71 \%$ of the variance in strain during ADL. It was also concluded that the method used in this study provides a quantitative and objective estimation of physical strain and may therefore be a useful tool to identify task difficulty during rehabilitation and to evaluate the results of task and physical training on the physical strain during ADL.

Keywords: paraplegia; tetraplegia; wheelchairs; heart rate; task difficulty.

\section{Introduction}

It has been suggested that wheelchair users with spinal cord injuries (SCI) lead a relatively sedentary life as a result of the loss of motor function. ${ }^{1}$ In previous studies it was shown that physical strain during daily life is in general low in individuals with SCI, ${ }^{2.3}$ but that individuals with cervical (and highthoracic) lesions have higher levels of physical strain throughout the day. ${ }^{3}$ Although

Correspondence: $\mathrm{T} \mathrm{W} \mathrm{J}$ Janssen at the above address. the physical strain during activities of daily living (ADL) was not of a magnitude and duration that it potentially could maintain or improve physical capacity, periods of peak strain frequently occurred, especially in subjects with high lesions. Periods of peak strain not only occurred during wheelchair ambulation, but also during activities such as making transfers, entering a car, household activities and personal care.

Although heart rate monitoring during daily life is suitable to reflect changing levels of strain throughout the day and to indicate 
strenuous activities, this method is not proficient to quantify physical strain during isolated tasks, since ADL are often performed simultaneously or successively without rest between activities, which makes it difficult to identify the physical strain provoked by separate activities. In addition, subjects perform ADL in various manners, using different assistive devices in buildings differently adjusted and under various environmental conditions. Environmental and situational factors, such as ambient temperature and humidity, and the ingestion of for example caffeine, tobacco or alcohol, may influence heart rate responses. Hence, in order to quantify physical strain during isolated daily tasks, standardised measurements are indispensable. For maximal wheelchair propulsion and for walking the physical strain has already been investigated in persons with $\mathrm{SCI},{ }^{4,5}$ but not for other ADL.

In various studies concerning able-bodied individuals it was suggested that individuals with higher levels of physical capacity to perform work have lower strain levels during all ADL. ${ }^{6,7}$ It has been suggested that this relationship also holds for individuals with SCI. ${ }^{1}$ The relationship between physical capacity and physiological responses during standardised forms of submaximal cyclic arm work has often been investigated. In many cases the performed task was arm cranking ${ }^{8-10}$ or propelling a wheelchair. ${ }^{5,11,12}$ Subjects with a higher physical capacity had relatively lower physical strain during the same absolute submaximal work load. Arm cranking, however, is not a daily activity for persons with SCI. Although wheelchair ambulation is an essential activity of this group and has been shown to provoke high levels of physical strain, ${ }^{13,14}$ other ADL such as making transfers, negotiating environmental barriers, or household activities might provoke even higher levels of strain. ${ }^{2,3}$ So far, the relationship between physical strain during daily activities other than wheelchair ambulation and physical capacity has never been investigated.

The purpose of this study was: (1) to quantify and compare the physical strain during standardised ADL among individuals with SCI and (2) to examine the relationship among physical strain, lesion level and parameters for physical capacity (peak oxygen uptake, maximal power output, isometric strength and sprint power).

\section{Methods}

\section{Subjects}

Forty-four men with long-standing SCI volunteered in this study after having signed an informed consent statement. All subjects used a hand-rim wheelchair and lived more or less independently at home. An interviewer-administered questionnaire assessed age, lesion level, the years after injury, and the hours of weekly sport participation. Subjects were grouped into four groups according to the level of their lesion (Table I).

Body mass was determined with the subjects sitting in light clothing on a Berkel scale. Skinfolds were determined with a Harpender calliper at the triceps, biceps, subscapular, and suprailiac sites.

Table I Subject characteristics. No significant differences were established among groups. The $n$ between brackets denotes the number of subjects with complete lesions

\begin{tabular}{lcccc}
\hline & $\begin{array}{c}\text { 1: } \begin{array}{c}n-\mathrm{C} 8 \\
(n=5)\end{array} \\
\text { Age (yrs) }\end{array}$ & $\begin{array}{c}2: \mathrm{T} 1-\mathrm{T} 5 \\
n=6 \\
(n=5)\end{array}$ & $\begin{array}{c}3: \mathrm{T} 6-\mathrm{T} 10 \\
n=15 \\
(n=9)\end{array}$ & $\begin{array}{c}4: \text { T11-L5 } \\
n=14 \\
(n=8)\end{array}$ \\
\hline Time since injury (yrs) & $32.9 \pm 9.4$ & $38.8 \pm 9.0$ & $33.4 \pm 12.4$ & $33.9 \pm 15.5$ \\
Body mass (kg) & $14.6 \pm 8.8$ & $15.3 \pm 8.5$ & $10.8 \pm 8.4$ & $7.3 \pm 6.2$ \\
Sum of 4 skinfolds (mm) & $81.2 \pm 14.9$ & $82.8 \pm 10.6$ & $78.6 \pm 16.0$ & $77.4 \pm 20.6$ \\
Sports activities (h week & $54.2 \pm 21.5$ & $61.9 \pm 24.0$ & $49.4 \pm 20.1$ & $52.3 \pm 31.3$ \\
\hline
\end{tabular}




\section{Protocol}

Tests were conducted between 10.00 and $17.00 \mathrm{~h}$ and were conducted in the fixed sequence as described below. The subjects started with a subset of standardised ADL (transfer to a bed, changing sheets, passing a side-hung door, transfer to a toilet, washing hands). At $11.00 \mathrm{~h}$ an isometric-strength test was conducted followed by a $30 \mathrm{~s}$ all-out sprint test in a wheelchair ergometer. After a $30 \mathrm{~min}$ rest period the subjects performed a second subset of ADL (transfer to a shower wheelchair and a shower seat, preparing lunch). After the lunch, subjects performed the tasks: washing up, negotiating a ramp and a curb, and entering a car. A discontinuous graded maximal wheelchair exercise test was conducted at 15.00$16.00 \mathrm{~h}$, at least $2 \mathrm{~h}$ after a light meal and after at least $1 \mathrm{~h}$ of rest.

\section{Standardised $A D L$}

The tasks included (1) making transfers to a bed, a (corbel) toilet, a shower seat, and shower wheelchair. The heights of the bed, toilet seat and shower seat were adjusted to the individual wheelchair seat height. During these three transfers the subjects were free to use hinged support rails (toilet and shower seat), grab rails (shower seat and bed) and stirrup grips (all three); (2) negotiating environmental obstacles: a side-hung door (width $0.9 \mathrm{~m}$ ) with a normal lever handle, an $0.08 \mathrm{~m}$ curb and a $6.25 \%$ graded, $8 \mathrm{~m}$ long ramp (recommended by the Dutch Council of Disabled ${ }^{15}$ ); (3) household tasks: changing sheets ( a pillow-case, a quilt cover and a fitted sheet), preparing a standard lunch (tea and a farmer's omelette on bread) and washing up in a wheelchairaccessible kitchen with an individually adjusted (height of the thighs plus $0.14 \mathrm{~m}$ ) kitchen-dresser; (4) entering a car, which took place outside and consisted of a transfer to the car and placement of the wheelchair in the car using an electric hoisting device; (5) washing hands using a single lever action tap and a basin with an adjusted height (height of the thighs plus $0.14 \mathrm{~m}$ ).

To let the subjects return to the resting state and to obtain a HR response exclusively due to the task, the subjects were instructed to sit quietly in their own wheel- chairs or on the transfer objects for approximately 2 min before and after each task. During all tasks the subjects were free to chose the speed of task performance.

\section{Physical strain}

Physical strain was estimated by the highest HR response (HRtask), expressed as a percentage of the heart rate reserve (\%HRR), provoked by the standardised tasks:

Physical strain (\%HRR)

$$
=\frac{\mathrm{HR}_{\text {task }}-\mathrm{HR}_{\text {rest }}}{\mathrm{HR}_{\text {peak }}-\mathrm{HR}_{\text {rest }}} \times 100 \%
$$

It was shown in a recent study ${ }^{19}$ that $\mathrm{HR}$ responses to non-steady-state tasks (transfers, curb ascents) can be reliably determined in wheelchair users with SCI. Several measures of the HR response were calculated in that study and it appeared that the highest HR during (or just after) the task, in contrast to a mean HR or an integrated HR (reflecting the total strain), was always easily identified, suggesting that the highest HR provoked by a task is the most useful parameter of the HR response to shortlasting non-steady-state tasks. The HR response was expressed relative to the heart rate reserve in order to be able to compare among subjects. The heart rate reserve, which is the functional range of HR, was defined as the difference between the lowest HR recorded during the day (HRrest) and the maximal HR (HRpeak) determined in a maximal exercise test, described in the next section.

HR was monitored continually throughout the day with a Sport Tester PE3000 (Polar Electro Inc., Finland), which stores every $5 \mathrm{~s}$ an average HR based on a pulseto-pulse time-averaging algorithm, using the last $15 \mathrm{R}-\mathrm{R}$ intervals of the ECG. Since the memory capacity of the Sport Tester is limited to approximately $80 \mathrm{~min}$ at a recording interval of $5 \mathrm{~s}$, the receivers were changed every $60-80 \mathrm{~min}$.

\section{Physical capacity}

To assess physical capacity, determinants of isometric strength, sprint power, aerobic 
power and maximum power output were obtained as described previously. ${ }^{16}$ Isometric strength and sprint power measurements were carried out on a stationary wheelchair ergometer. ${ }^{17}$ The isometricstrength test consisted of $5 \mathrm{~s}$ maximal isometric force exertions on five different positions on the blocked hand rims of the ergometer $\left(-15^{\circ}, 0^{\circ}, 15^{\circ}, 30^{\circ}\right.$ and $60^{\circ}$ with respect to top dead centre) in random order with a 2 min rest period between each force exertion. The effective force, which is the applied force tangent to the rim, was calculated by dividing the measured effective torque (mean of left and right side) by the radius of the rims. Maximal isometric strength $\left(\mathrm{F}_{\text {iso }}\right)$ was determined by averaging the maximum effective force values of the five trials and denotes a wheelchair-specific strength.

The sprint test consisted of a $30 \mathrm{~s}$ all-out effort. Since subjects varied considerably in age, level of lesion and activity level, the group was divided into three subgroups according to their functional ability, based on the forementioned variables. Older subjects with high lesions were grouped into a low-level ability group and young active subjects with low lesions were grouped into a high-level ability group. The remaining subjects (e.g. inactive middle-aged subjects) formed the mid-level ability group. During the all-out effort the resistance level was normalised at $0.25,0.50$ or $0.75 \mathrm{~N} \mathrm{~kg}^{-1}$ body mass for the three groups. The mean power during the $30 \mathrm{~s}$ test period (P30) was determined from the product of angular velocity and effective torque and taken as a measure of sprint power.

To determine aerobic power $\left(\dot{\mathrm{VO}}_{2}\right.$ peak $)$ and maximum power output (POmax), each subject performed a graded exercise test in his own daily-use wheelchair on a motordriven treadmill (Enraf Nonius, model 3446 , belt width $1.25 \mathrm{~m}$, length $3.0 \mathrm{~m}$ ) following a discontinuous protocol. Each of the above mentioned groups used a slightly different protocol to prevent too large PO increments or to avoid excessive test time. The protocol consisted of $3 \mathrm{~min}$ exercise bouts at a constant velocity of $0.83,1.11$ or $1.39 \mathrm{~ms}^{-1}$ (for the three groups), separated by 2 min relative test intervals, during which the velocity was reduced to $0.56,0.83$ or $1.11 \mathrm{~ms}^{-1}$, respectively. The initial PO was equal to the drag of the wheelchair-user combination (determined in a drag test according to Woude et al $^{18}$ ) times the belt velocity. Every subsequent exercise bout PO was increased with $0.05,0.10$, or 0.15 (for the three groups, respectively) W per $\mathrm{kg}$ total mass (subject + wheelchair) by imposing an additional resisting force upon the wheelchair through a pulley system. A test was ended when the subject could no longer maintain his position on the belt.

During the exercise bouts $\dot{\mathrm{V}} \mathrm{O}_{2}$ was measured with an Oxycon $\mathrm{Ox} 4$ (Mijnhardt) with sampling periods of $30 \mathrm{~s}$. Calibration was performed prior to each test with reference gases. $\mathrm{VO}_{2}$ peak was the highest value recorded during the test and POmax was the PO when $\dot{\mathrm{VO}} 2$ peak was achieved. HR was recorded continuously using a Sport Tester PE3000 with a $5 \mathrm{~s}$ storage interval. HRpeak was the highest $H R$ recorded during the test. A mean HR (expressed as $\%$ HRR) and $\dot{\mathrm{VO}}_{2}$ were calculated during the third minute of each exercise period in order to investigate the relationships between \% HRR and \% POmax (PO expressed as a percentage of POmax) and between $\% \mathrm{HRR}$ and $\% \dot{\mathrm{VO}}_{2}$ peak.

\section{Statistics}

Differences in physical strain during the tasks and in physical capacity among lesion groups were analysed with a two-way ANOVA (factors: lesion level (groups 1-4) and completeness of lesion $)(p<0.05)$. When appropriate, a Tukey multiple range test was applied for identification of significant differences among groups. Differences in physical strain among the various tasks were investigated with a repeated measures MANOVA. Using multiple dependent $t$ tests, employing the Bonferroni inequality to keep overall $\alpha$ at 0.05 , significant $(p<0.001)$ differences among tasks were identified. Pearson correlations determined the relationship between physical capacity and strain during the tasks. A multiple regression procedure, with parameters of physical capacity $\left(\mathrm{VO}_{2}\right.$ peak, POmax, $\mathrm{F}_{\text {iso }}$, P30), lesion level, years after injury, age, 
body mass, sum of four skinfolds and hours of sports activities as independent variables, determined the most important factors in predicting physical strain. For this purpose, each lesion level was assigned an arbitrary number from 1 to $22, \mathrm{C} 4$ being 1 and L5 being 22 . If a lesion concerned more than one segment, an intermediate number was given (e.g. C4/5 was given the number 1.5 ). Inclusion level was set at $p<0.05$. Pearson correlations determined the relationship between \%HRR, \% POmax and \% $\dot{V O}_{2}$ peak for each subject and for each group of subjects.

\section{Results}

\section{Physical strain}

The Sport Tester appeared to be a reliable recording device: less than $1 \%$ of all data were lost. In addition, no interference from electromagnetic sources was observed during the day. Not all subjects were able to perform all tasks independently leading to drop-outs during transfer to bed $(n=4)$, transfer to toilet $(n=1)$, transfer to shower wheelchair $(n=6)$, transfer to shower seat $(n=2)$, changing sheets $(n=1)$, ascending curb $(n=5)$, and entering car $(n=7)$. In addition, since some subjects arrived late or had to leave in time, some tasks (especially preparing lunch, washing up, ascending ramp and curb) were not performed by all subjects which reduced the number of subjects who performed all tasks to 24 , the results of whom were used to compare physical strain among tasks (Fig 1). No significant trend in strain during the tasks nor in HR between tasks as a result of the sequence chosen was observed

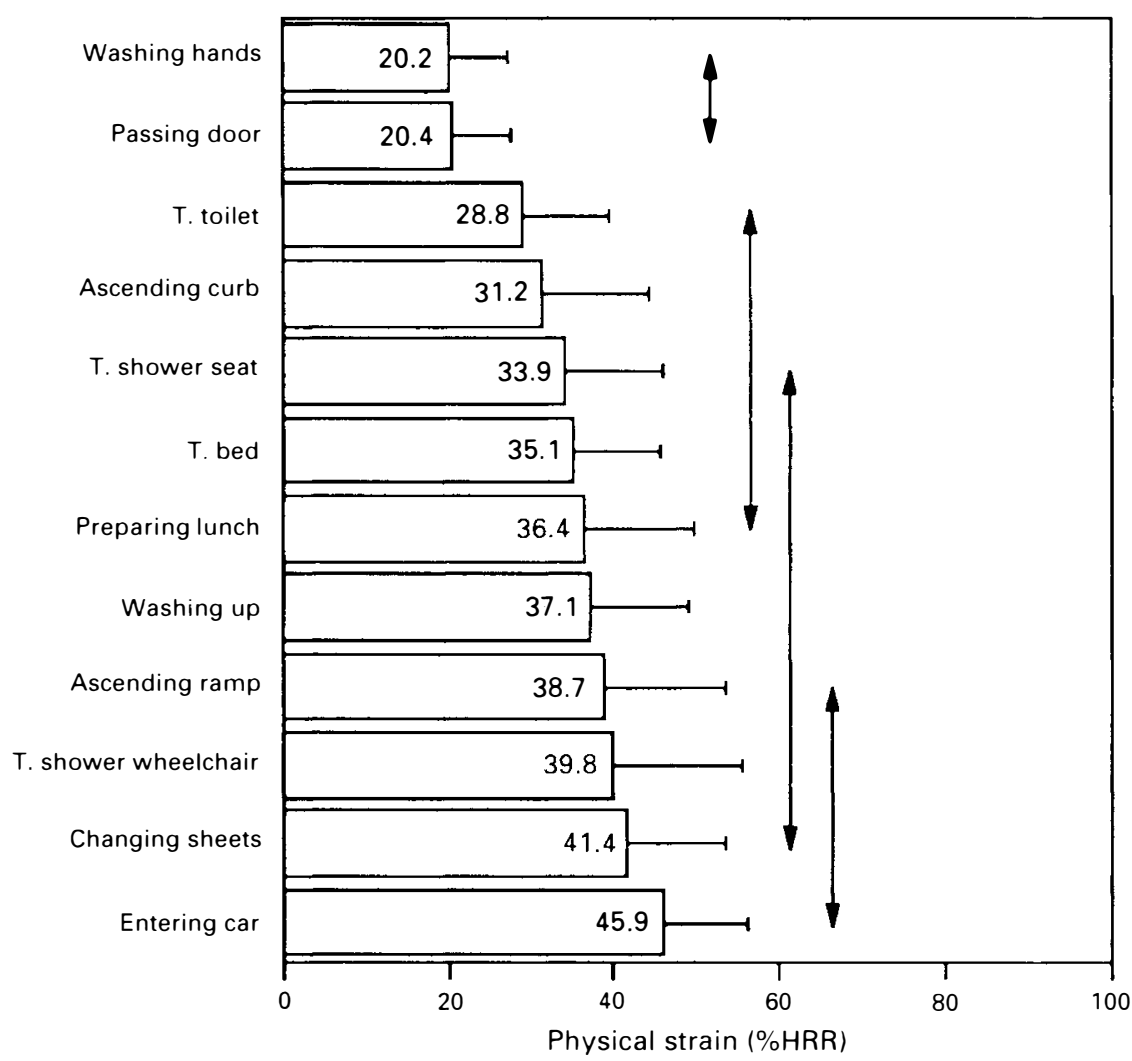

Figure 1 Physical strain provoked by the 12 tasks $(n=24)$. The tasks are ordered according to the level of strain. Tasks not linked by the same arrow are significantly different $(p<0.001)$. 
(MANOVA). The large standard deviations indicate the vast differences among subjects. Entering the car provoked the highest physical strain (46\%HRR). Washing hands and passing a door provoked significantly $(p<0.001)$ lower strain $(20 \%$ HRR $)$ than all other tasks.

Table II displays the mean $( \pm S D)$ values for physical strain provoked by the various tasks for the four lesion groups. ANOVA revealed that completeness of the lesion had no significant main effect on physical strain and hence data from subjects with complete and incomplete lesions are presented together. The subjects with tetraplegia (group 1) had significantly higher levels of strain than the groups with the lowest lesions (groups 3 and 4) during all tasks. Although the physical strain for the subjects with high-level paraplegia (group 2) seemed to be higher than for groups 3 and 4 , a significant difference was only established for the transfer to the toilet (42 vs 27/29 $\%$ HRR) and for changing sheets (53 vs $40 / 36 \%$ HRR). Comparison between groups 3 and 4 showed few significant differences.

Physical capacity

Table III indicates that for physical capacity a relationship with lesion level was obvious. In general, subjects with higher lesions had a lower physical capacity than those with lower lesions. In spite of very large standard deviations within groups, significant differences between subjects with tetraplegia and groups 3 and 4 were established for all parameters.

HRpeak was significantly lower among those with tetraplegia than among all groups of subjects with paraplegia (Table III). HRrest among subjects with tetraplegia and in group 2 was also significantly lower than in groups 3 and 4 . HRR was significantly lower among subjects with tetraplegia than in all groups with paraplegia.

Heart rate (\%HRR) during submaximal wheelchair propulsion on the treadmill was significantly related to \% POmax and $\% \dot{V O}_{2}$ peak for each subject group (Table IV). Also the individual correlation coefficients were significant and in most cases very high. Figure 2 shows examples of these relationships in subjects from each group.

Relationship between physical capacity and physical strain

All parameters for physical capacity were inversely related to physical strain during the tasks, which was significant for most relations with $\mathrm{F}_{\text {iso }}$ or $\mathrm{P} 30$ and for all relations
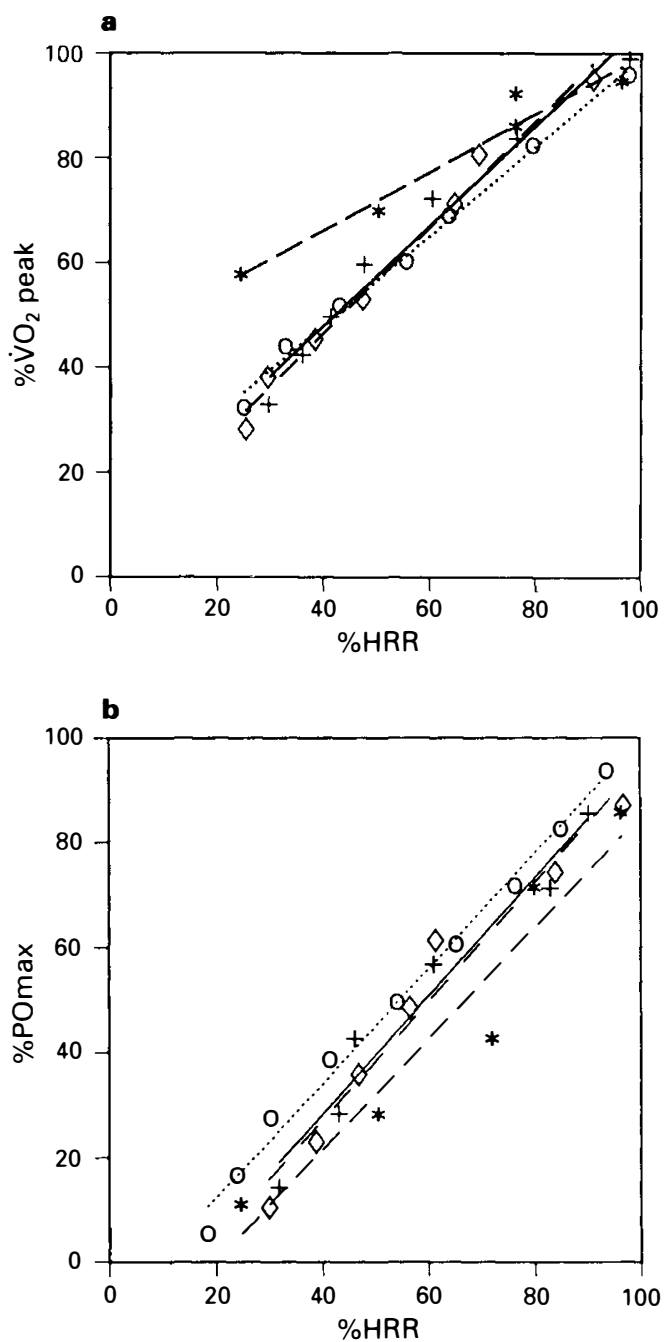

Figure 2 Examples of the relationships between $\% \mathrm{HRR}$ and submaximal relative power output (\% POmax) and \%HRR and submaximal oxygen uptake $\left(\% \mathrm{VO}_{2}\right.$ peak $)$ for a subject from each lesion level group. All subjects have complete lesions. $\quad *=\mathrm{C} 6 / 8 ; \quad+=\mathrm{T} 5 ; \quad \diamond=\mathrm{T} 7$; $\mathrm{O}=\mathrm{T} 12$. 
Table II Physical strain (mean \pm SD), provoked by the various tasks, among the four different subject groups

\begin{tabular}{|c|c|c|c|c|c|c|c|c|c|}
\hline Task & $n$ & 1: $\mathrm{C} 4-\mathrm{C} 8$ & $n$ & 2: T1-T5 & $n$ & 3:T6-T10 & $n$ & 4: T10-L5 & $\begin{array}{l}\text { Significantly } \\
\text { different groups }\end{array}$ \\
\hline T. WC - Bed & 6 & $68.4 \pm 7.0$ & 5 & $35.2 \pm 8.5$ & 15 & $33.2 \pm 4.7$ & 13 & $33.3 \pm 13.9$ & $1-2,3,4$ \\
\hline T. WC - Toilet & 6 & $59 .() \pm 7.2$ & 6 & $42.1 \pm 13.6$ & 14 & $26.5 \pm 13.1$ & 13 & $29.2 \pm 5.7$ & $1-2,3,4 ; 2-3,4$ \\
\hline T. WC - Shower WC & 5 & $65.5 \pm 12.2$ & 6 & $48.2 \pm 22.0$ & 12 & $36.2 \pm 13.2$ & 13 & $40.9 \pm 11.3$ & $1-3,4$ \\
\hline T. WC - Shower seat & 6 & $65.6 \pm 10.3$ & 6 & $46.7 \pm 19.9$ & 15 & $28.0 \pm 7.7$ & 13 & $38.6 \pm 11.0$ & $1-2,3,4 ; 3-2,4$ \\
\hline Washing hands & 7 & $34.2 \pm 9.6$ & 5 & $28.1 \pm 22.2$ & 14 & $19.7 \pm 6.4$ & 13 & $19.2 \pm 5.4$ & $1-3,4$ \\
\hline Changing sheets & 8 & $65.2 \pm 10.5$ & 6 & $52.9 \pm 18.8$ & 15 & 4() $.1 \pm 6.1$ & 13 & $35.7 \pm 7.2$ & $1-2,3,4 ; 2-3,4$ \\
\hline Preparing lunch & 5 & $63.1 \pm 4.5$ & 4 & $42.6 \pm 12.0$ & 13 & $33.8 \pm 11.8$ & 13 & $30.3 \pm 7.8$ & $1-2,3,4$ \\
\hline Washing up & 5 & $58.3 \pm 5.3$ & 4 & $41.4 \pm 6.5$ & 11 & $36.1 \pm 13.4$ & 12 & 3() $.7 \pm 9.2$ & $1-2,3,4$ \\
\hline Passing door & 9 & $39.8 \pm 14.3$ & 6 & $27.3 \pm 14.9$ & 15 & $19.1 \pm 6.8$ & 13 & $19.8 \pm 5.5$ & $1-3,4$ \\
\hline Ascending ramp & 9 & $63.6 \pm 15.4$ & 6 & $46.1 \pm 21.9$ & 13 & $36.0 \pm 13.0$ & 13 & $35.6 \pm 15.9$ & $1-2,3,4$ \\
\hline Ascending curb & 6 & $58.1 \pm 11.6$ & 5 & $32.7 \pm 18.3$ & 13 & $31.5 \pm 13.8$ & 11 & $30.7 \pm 10.5$ & $1-2,3,4$ \\
\hline Entering car & 5 & $75.8 \pm 12.3$ & 5 & $54.1 \pm 12.2$ & 13 & $43.0 \pm 6.7$ & 14 & $42.9 \pm 10.5$ & $1-2,3,4$ \\
\hline
\end{tabular}

WC: wheclchair; $n$ : number of subjects who performed the task.

Table III Mean $( \pm S D)$ values for isometric strength $\left(\mathrm{F}_{\mathrm{iso}}\right)$, sprint power $(\mathrm{P} 3())$, peak oxygen uptake ( $\dot{V}_{2}$ peak), and maximal power output (POmax) among the four groups

\begin{tabular}{|c|c|c|c|c|c|c|}
\hline & & $\begin{array}{c}1: C 4-C 8 \\
n=9\end{array}$ & $\begin{array}{c}2: \mathrm{T} 1-\mathrm{T} 5 \\
n=6\end{array}$ & $\begin{array}{c}\text { 3: Т6-T } 10 \\
n=15\end{array}$ & $\begin{array}{c}4: \mathrm{T} 10-\mathrm{L} 5 \\
n=14\end{array}$ & $\begin{array}{c}\text { Significantly } \\
\text { different groups }\end{array}$ \\
\hline \multirow[t]{2}{*}{$\mathrm{F}_{\mathrm{iso}}$} & $(\mathrm{N})$ & $118.4 \pm 44.7$ & $172.2 \pm 33.5$ & $209.2 \pm 52.0$ & $213.2 \pm 56.3$ & $1-2,3,4$ \\
\hline & $(\mathrm{N} k g$ I) & $1.48 \pm 0.55$ & $2.12 \pm 0.57$ & $2.75 \pm 0.76$ & $2.87 \pm 0.86$ & $1-3,4$ \\
\hline \multirow[t]{2}{*}{ P30 } & $(W)^{\circ}$ & $42.4 \pm 26.4$ & $78.5 \pm 41.6$ & $92.3 \pm 36.6$ & $103.2 \pm 30.8$ & $1-2,3,4$ \\
\hline & $\left(\mathrm{W} \mathrm{kg}^{-1}\right)$ & $0.51 \pm 0.25$ & $0.85 \pm 0.33$ & $1.22 \pm 0.48$ & $1.45 \pm 0.48$ & $1-3 ; 1,2-4$ \\
\hline \multirow{2}{*}{$\dot{\mathrm{V}} \mathrm{O}_{2}$ peak } & $\left(1 \min ^{-1}\right)$ & $1.09 \pm 0.25$ & $1.45 \pm 0.35$ & $1.61 \pm 0.44$ & $1.92 \pm 0.40^{*}$ & $1-3 ; 1,2,3-4$ \\
\hline & $\left(\mathrm{ml} \mathrm{kg} \mathrm{kg}^{-1} \min ^{-1}\right)$ & $13.6 \pm 3.0$ & $17.6 \pm 4.0$ & $21.2 \pm 6.6$ & $26.2 \pm 7.6^{*}$ & $1-3 ; 1,2,3-4$ \\
\hline \multirow[t]{2}{*}{ POmax } & $(\mathrm{W})$ & $29.6 \pm 10.7$ & $55.0 \pm 22.0$ & $65.8 \pm 24.7$ & $77.2 \pm 20.2^{*}$ & $1-2,3,4$ \\
\hline & $\left(\mathrm{Wkg} \cdot{ }^{1}\right)$ & $0.37 \pm 0.11$ & $0.68 \pm 0.29$ & $0.86 \pm 0.36$ & $1.06 \pm 0.37^{*}$ & $1-3,4$ \\
\hline HRpeak & (bpm) & $129.8 \pm 14.6$ & $165.2 \pm 18.4$ & $186.5 \pm 26.0$ & $181.1 \pm 17.8$ & $1-2,3,4$ \\
\hline HRrest & (bpm) & $56.3 \pm 8.1$ & $59.3 \pm 10 .()$ & $70.0 \pm 12.0$ & $70.1 \pm 12.8$ & $1,2-3,4$ \\
\hline HRR & (beats) & $73.4 \pm 16.5$ & $105.8 \pm 18.4$ & $116.5 \pm 20.8$ & $111.0 \pm 21.1$ & $1-2,3,4$ \\
\hline
\end{tabular}

${ }^{*} n=13$ 
Table IV Relationship between heart rate (\%HRR) and submaximal power output (\% POmax) and between heart rate (\%HRR) and $\% \dot{\mathrm{VO}}{ }_{2}$ peak among the four groups of subjects. Regression equation is based on all data points from a group. The individual correlations (mean $\pm \mathrm{SD}$, range) for each group are presented in the right column

\begin{tabular}{|c|c|c|c|c|c|}
\hline Subject group & $\begin{array}{l}\text { Data } \\
\text { points }\end{array}$ & & $\begin{array}{l}\text { Signifi- } \\
\text { cance }\end{array}$ & $\begin{array}{l}\text { Group } \\
\text { correlations }\end{array}$ & $\begin{array}{l}\text { Individual } \\
\text { correlations }\end{array}$ \\
\hline \multirow[t]{2}{*}{$\mathrm{C} 4-\mathrm{C} 8$} & 41 & $\begin{aligned} \% \text { POmax }= & 1.03 \pm 0.13 \% \mathrm{HRR} \\
& -11.67 \pm 8.84\end{aligned}$ & $\begin{array}{l}0.000 \\
0.194\end{array}$ & 0.79 & $\begin{array}{l}0.91 \pm 0.11 \\
0.65-0.98\end{array}$ \\
\hline & 41 & $\begin{aligned} \% \dot{\mathrm{VO}}_{2} \text { peak }= & 0.72 \pm 0.07 \% \mathrm{HRR} \\
& +26.42 \pm 4.64\end{aligned}$ & $\begin{array}{l}0.000 \\
0.000\end{array}$ & 0.86 & $\begin{array}{c}0.95 \pm 0.07 \\
0.80-0.99\end{array}$ \\
\hline \multirow[t]{2}{*}{$\mathrm{T} 1-\mathrm{T} 5$} & 31 & $\begin{aligned} \% \text { POmax }= & 0.96 \pm 0.10 \% \mathrm{HRR} \\
& +1.25 \pm 5.72\end{aligned}$ & $\begin{array}{l}0.000 \\
0.828\end{array}$ & 0.87 & $\begin{array}{c}0.96 \pm 0.04 \\
0.90-1.00\end{array}$ \\
\hline & 31 & $\begin{aligned} \% \dot{\mathrm{VO}} \mathrm{O}_{2} \text { peak }= & 0.74 \pm 0.07 \% \mathrm{HRR} \\
& +28.48 \pm 3.75\end{aligned}$ & $\begin{array}{l}0.000 \\
0.000\end{array}$ & 0.90 & $\begin{array}{c}0.96 \pm 0.04 \\
0.91-1.00\end{array}$ \\
\hline \multirow[t]{2}{*}{ T6-T10 } & 98 & $\begin{aligned} \% \text { POmax }= & 0.99 \pm 0.04 \% \mathrm{HRR} \\
& -5.75 \pm 2.61\end{aligned}$ & $\begin{array}{l}0.000 \\
0.030\end{array}$ & 0.92 & $\begin{array}{c}0.98 \pm 0.03 \\
0.91-1.00\end{array}$ \\
\hline & 98 & $\begin{aligned} \% \dot{\mathrm{V}} \mathrm{O}_{2} \text { peak }= & 0.78 \pm 0.03 \% \mathrm{HRR} \\
& +20.96 \pm 1.87\end{aligned}$ & $\begin{array}{l}0.000 \\
0.000\end{array}$ & 0.94 & $\begin{array}{c}0.96 \pm 0.07 \\
0.72-1.00\end{array}$ \\
\hline \multirow[t]{2}{*}{ T11-L5 } & 122 & $\begin{aligned} \% \text { POmax }= & 1.10 \pm 0.04 \% \mathrm{HRR} \\
& -10.67 \pm 2.24\end{aligned}$ & $\begin{array}{l}0.000 \\
0.000\end{array}$ & 0.94 & $\begin{array}{c}0.98 \pm 0.02 \\
0.92-1.00\end{array}$ \\
\hline & 112 & $\begin{aligned} \% \dot{\mathrm{V}} \mathrm{O}_{2} \text { peak }= & 0.85 \pm 0.03 \% \mathrm{HRR} \\
& +10.85 \pm 1.77\end{aligned}$ & $\begin{array}{l}0.000 \\
0.000\end{array}$ & 0.94 & $\begin{array}{c}0.98 \pm 0.02 \\
0.92-1.00\end{array}$ \\
\hline
\end{tabular}

with $\dot{\mathrm{V}} \mathrm{O}_{2}$ peak or POmax (Table V). Pearson's $r$ was in general notably higher when only subjects with complete lesions were used in the analysis. Parameters determined during the maximal exercise test (POmax and $\dot{\mathrm{V}}{ }_{2}$ peak) displayed correlations ranging from -0.46 to -0.82 , whereas $F_{\text {iso }}$ and P30 had a weaker relationship with physical strain $(r:-0.34$ to -0.72$)$. As an example, Figure 3 shows the relationship between POmax and strain during the curb ascent.

Since in general correlation coefficients were notably higher for the group with complete lesions, only these subjects $(n=27)$ were used in the regression procedures with physical strain (\%HRR) as the dependent variable and parameters of physical capacity, lesion level, years after injury, age, body mass, sum of four skinfolds and hours of sports activities weekly as independent varables. Table VI shows that after multiple regression analyses $37-71 \%$ of the variance in physical strain for the various tasks could be explained. The regression equation for washing hands explained only $37 \%$ of the variance in strain. POmax was the most important predictor of physical strain and appeared in eight of the 12 regression equations, whereas $\mathrm{VO}_{2}$ peak was more important in four of the equations. In addition to these parameters, $\mathrm{F}_{\text {iso }}$ explained a significant extra part of the variance in strain during the transfers (except for the transfer to the shower wheelchair), the curb ascent, and while entering the car. It appeared that subjects with equal POmax or $\dot{\mathrm{V}} \mathrm{O}_{2}$ peak but with a higher $\mathrm{F}_{\text {iso }}$ had a lower strain during these tasks. Age was entered into the equations for the transfer to the bed and the ramp ascent indicating that older subjects with an equal physical capacity had lower levels of strain during these tasks. For the household tasks, washing hands, and passing the door, absolute parameters appeared in the equations, whereas in the equations for all other tasks a parameter relative to body mass was entered.

\section{Discussion}

In this study physical strain was estimated using the highest HR response provoked by the task, expressed as a percentage of the 
Table V Correlation coefficients between physical strain (\%HRR) during the standardised tasks and parameters for physical capacity

\begin{tabular}{|c|c|c|c|c|c|c|c|c|c|c|c|c|c|c|}
\hline & & & $\begin{array}{c}\mathrm{T} \\
\text { Bed }\end{array}$ & $\begin{array}{c}\mathrm{T} \\
\text { Toilet }\end{array}$ & $\begin{array}{c}\mathrm{T} \\
\text { Shower } \\
\text { seat }\end{array}$ & $\begin{array}{c}\mathrm{T} \\
\text { Shower } \\
\text { WC }\end{array}$ & $\begin{array}{l}\text { Wash } \\
\text { hands }\end{array}$ & $\begin{array}{l}\text { Change } \\
\text { sheets }\end{array}$ & $\begin{array}{l}\text { Prepare } \\
\text { lunch }\end{array}$ & $\begin{array}{l}\text { Wash } \\
\text { up }\end{array}$ & $\begin{array}{c}\text { Passing } \\
\text { door }\end{array}$ & $\begin{array}{l}\text { Ramp } \\
\text { ascent }\end{array}$ & $\begin{array}{l}\text { Curb } \\
\text { ascent }\end{array}$ & $\begin{array}{l}\text { Enter } \\
\text { car }\end{array}$ \\
\hline \multirow[t]{4}{*}{$\mathrm{F}_{\mathrm{iss}}$} & $(\mathrm{N})$ & To & -0.49 & -0.55 & -0.48 & $-0.34^{*}$ & -0.45 & -0.55 & -0.52 & -0.54 & -0.59 & -0.48 & -0.50 & $-0.39^{*}$ \\
\hline & & $\mathrm{C}$ & -0.64 & -0.59 & -0.59 & $-0.40^{*}$ & $-0.36^{*}$ & -0.57 & -0.64 & -0.59 & -0.67 & -0.52 & -0.65 & -0.55 \\
\hline & $\left(\mathrm{N} \mathrm{kg}^{-1}\right)$ & To & -0.49 & -0.61 & -0.55 & -0.49 & -0.40 & -0.43 & -0.40 & -0.43 & -0.46 & -0.46 & $-0.37 *$ & -0.45 \\
\hline & & $\mathrm{C}$ & -0.64 & -0.72 & -0.62 & -0.56 & -0.34 & -0.46 & $-0.48^{*}$ & $-0.37 *$ & -0.52 & $-0.46^{*}$ & $-0.47^{*}$ & -0.55 \\
\hline \multirow[t]{4}{*}{ P30 } & (W) & To & -0.45 & -0.45 & -0.41 & $-0.34^{*}$ & -0.54 & -0.56 & -0.54 & -0.53 & -0.55 & -0.53 & -0.45 & $-0.39 *$ \\
\hline & & $\mathrm{C}$ & -0.58 & -0.48 & -0.54 & $-0.39 *$ & -0.50 & -0.62 & -0.67 & -0.62 & -0.65 & -0.62 & -0.62 & -0.46 \\
\hline & $\left(\mathrm{W} \mathrm{kg}^{-1}\right)$ & To & -0.53 & -0.57 & -0.53 & -0.51 & -0.52 & -0.52 & -0.51 & -0.53 & -0.50 & -0.57 & -0.48 & -0.51 \\
\hline & & $\mathrm{C}$ & -0.66 & -0.69 & -0.66 & -0.61 & -0.50 & -0.58 & -0.67 & -0.57 & -0.60 & -0.66 & -0.64 & -0.62 \\
\hline \multirow[t]{4}{*}{$\mathrm{VO}_{2}$ peak } & $\left(1 \min ^{-1}\right)$ & To & -0.49 & -0.59 & -0.54 & -0.46 & -0.54 & -0.70 & -0.53 & -0.68 & -0.62 & -0.56 & -0.60 & -0.61 \\
\hline & & $\mathrm{C}$ & -0.67 & -0.67 & -0.69 & -0.55 & -0.52 & -0.80 & -0.71 & -0.78 & -0.70 & -0.67 & -0.81 & -0.75 \\
\hline & $\left(\mathrm{ml} \mathrm{kg}^{-1} \min ^{-1}\right)$ & To & -0.46 & -0.61 & -0.57 & -0.57 & -0.46 & -0.53 & -0.41 & -0.55 & -0.47 & -0.52 & -0.48 & -0.61 \\
\hline & & $\mathrm{C}$ & -0.63 & -0.75 & -0.69 & -0.69 & -0.50 & -0.62 & -0.55 & -0.57 & -0.53 & -0.60 & -0.64 & -0.70 \\
\hline \multirow[t]{4}{*}{ POmax } & $(\mathrm{W})$ & To & -0.59 & -0.63 & -0.60 & -0.58 & -0.63 & -0.67 & -0.63 & -0.73 & -0.63 & -0.66 & -0.67 & -0.63 \\
\hline & & $\mathrm{C}$ & -0.69 & -0.69 & -0.70 & -0.66 & -0.61 & -0.71 & -0.75 & -0.81 & -0.70 & -0.73 & -0.82 & -0.72 \\
\hline & $\left(\mathrm{W} \mathrm{kg}^{-1}\right)$ & To & -0.55 & -0.63 & -0.61 & -0.65 & -0.55 & -0.55 & -0.54 & -0.65 & -0.52 & -0.63 & -0.59 & -0.62 \\
\hline & & $\mathrm{C}$ & -0.66 & -0.75 & -0.69 & -0.75 & -0.54 & -0.60 & -0.65 & -0.68 & -0.59 & -0.69 & -0.73 & -0.69 \\
\hline
\end{tabular}

To $=$ total group; $\mathrm{C}=$ group subjects with complete lesions; $\mathrm{T}=$ transfer; ${ }^{*}$ not significant $(p>0.05)$ 
Table VI Results of the multiple regresion analyses to predict physical strain (\%HRR) during the standardised tasks

\begin{tabular}{|c|c|c|c|c|}
\hline Task & Independent variables & SE & $p$-value & Cumulative $\mathrm{R}^{2}$ \\
\hline \multirow[t]{4}{*}{ Transfer WC-Bed } & $\% \mathrm{HRR}=-0.23 \mathrm{POmax}(\mathrm{W})$ & 0.08 & 0.006 & 0.48 \\
\hline & $-8.98 \mathrm{~F}_{\text {iso }}\left(\mathrm{N} \mathrm{kg}^{-1}\right)$ & 2.39 & 0.001 & 0.59 \\
\hline & -0.56 Age (yrs) & 0.21 & 0.017 & 0.69 \\
\hline & +95.65 & 10.41 & 0.000 & \\
\hline \multirow[t]{3}{*}{ Transfer WC-Toilet } & $\% \mathrm{HRR}=-1.20 \mathrm{VO}_{2}$ peak $\left(\mathrm{ml} \mathrm{kg}^{-1} \mathrm{~min}^{-1}\right)$ & 0.27 & 0.000 & 0.56 \\
\hline & $-0.09 \mathrm{~F}_{\text {iso }}(\mathrm{N})$ & 0.04 & 0.025 & 0.66 \\
\hline & +80.23 & 7.54 & 0.000 & \\
\hline \multirow[t]{2}{*}{ Transfer WC-Shower WC } & $\% \mathrm{HRR}=-30.47 \mathrm{POmax}\left(\mathrm{W} \mathrm{kg} \mathrm{kg}^{-1}\right)$ & 5.96 & 0.000 & 0.57 \\
\hline & +72.29 & 6.00 & 0.000 & \\
\hline \multirow[t]{3}{*}{ Transfer WC-Shower seat } & $\% \mathrm{HRR}=-0.36 \mathrm{POmax}(\mathrm{W})$ & 0.11 & 0.003 & 0.49 \\
\hline & $-7.13 \mathrm{~F}_{\text {iso }}\left(\mathrm{N} \mathrm{kg}^{-1}\right)$ & 3.05 & 0.029 & 0.59 \\
\hline & +83.32 & 7.90 & 0.000 & \\
\hline \multirow[t]{2}{*}{ Washing hands } & $\% \mathrm{HRR}=-0.26 \mathrm{POmax}(\mathrm{W})$ & 0.07 & 0.002 & 0.37 \\
\hline & +39.55 & 5.17 & 0.000 & \\
\hline \multirow[t]{3}{*}{ Changing sheets } & $\% \mathrm{HRR}=-17.71 \dot{\mathrm{VO}} 2$ peak $\left(1 \mathrm{~min}^{-1}\right)$ & 4.69 & 0.001 & 0.64 \\
\hline & -1.06 Lesion level & 0.45 & 0.028 & 0.71 \\
\hline & +86.83 & 5.97 & 0.000 & \\
\hline \multirow[t]{2}{*}{ Preparing lunch } & $\% \mathrm{HRR}=-0.40 \mathrm{POmax}(\mathrm{W})$ & 0.09 & 0.000 & 0.56 \\
\hline & +66.18 & 6.15 & 0.000 & \\
\hline \multirow[t]{2}{*}{ Washing up } & $\% \mathrm{HRR}=-0.42 \mathrm{POmax}(\mathrm{W})$ & 0.08 & 0.000 & 0.65 \\
\hline & +67.89 & 5.66 & 0.000 & \\
\hline \multirow[t]{2}{*}{ Passing door } & $\% \mathrm{HRR}=-20.02 \dot{\mathrm{VO}} \mathrm{O}_{2}$ peak $\left(1 \mathrm{~min}^{-1}\right)$ & 4.04 & 0.000 & 0.50 \\
\hline & +57.45 & 6.75 & 0.000 & \\
\hline \multirow[t]{3}{*}{ Ascending ramp } & \% HRR = -35.87 POmax ( $\left.\mathrm{W} \mathrm{kg}^{-1}\right)$ & 6.97 & 0.000 & 0.47 \\
\hline & -0.60 Age $(\mathrm{yrs})$ & 0.29 & 0.049 & 0.56 \\
\hline & +96.00 & 13.56 & 0.000 & \\
\hline \multirow[t]{3}{*}{ Ascending curb } & $\%$ HRR $=-23.66$ POmax $\left(\mathrm{W} \mathrm{kg}^{-1}\right)$ & 5.68 & 0.001 & 0.53 \\
\hline & $-0.13 \mathrm{~F}_{\mathrm{iso}}(\mathrm{N})$ & 0.04 & 0.005 & 0.70 \\
\hline & +85.91 & 7.94 & 0.000 & \\
\hline \multirow[t]{3}{*}{ Entering car } & $\% \mathrm{HRR}=-21.63 \dot{\mathrm{VO}}_{2}$ peak $\left(1 \mathrm{~min}^{-1}\right)$ & 4.54 & 0.000 & 0.56 \\
\hline & $-6.42 \mathrm{~F}_{\mathrm{iso}}\left(\mathrm{N} \mathrm{kg}^{-1}\right)$ & 2.35 & 0.013 & 0.68 \\
\hline & +106.38 & 8.89 & 0.00 & \\
\hline
\end{tabular}

$\mathrm{T}=$ transfer $; \mathrm{WC}=$ wheelchair $; \mathrm{SE}=$ standard error of the regression coefficient. 


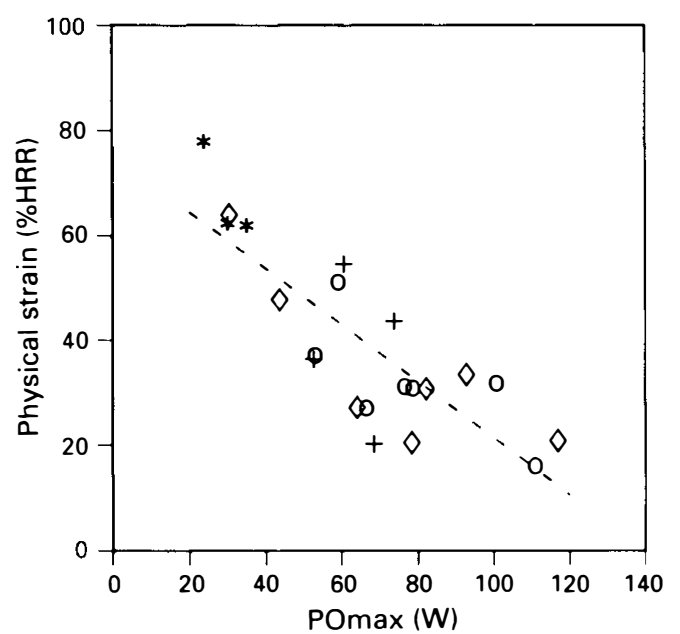

Figure 3 Relationship $(r=-0.82) \quad$ between maximal power output (POmax) and physical strain (\%HRR) during the curb ascent for the subjects with complete lesions $(n=21)$. $*=\mathrm{C} 4-\mathrm{C} 8 ; \quad+=\mathrm{T} 1-\mathrm{T} 5 ; \quad \diamond=\mathrm{T} 6-\mathrm{T} 10 ; \quad \bigcirc=$ T11-L5.

HRR. It has to be realised, however, that the highest HR as determined in this study is not equal to a highest HR derived from the shortest $\mathrm{R}-\mathrm{R}$-interval but is actually a highest observed mean value over $15 \mathrm{R}-\mathrm{R}$ intervals, as a result of the calculating method of the Sport Tester PE3000 which calculates continuously an average HR over the last $15 \mathrm{R}$-R-intervals using a pulse-topulse averaging algorithm. ${ }^{20}$ Although the real HR may therefore be slightly higher, the clinical significance of one or two beats higher than recorded by the Sport Tester can be questioned.

The linear relationships between \%HRR and \%POmax and between \%HRR and $\% \dot{\mathrm{V}} \mathrm{O}_{2}$ peak were significant in all groups. Strong correlations were found in each group with somewhat higher standard deviations in the group subjects with tetraplegia. In spite of this, the mean correlations for \% HRR-\% POmax (0.91) and for $\%$ HRR-\% $\dot{\mathrm{VO}}_{2}$ peak (0.95) indicate that most subjects with tetraplegia exhibit strong correlations for these parameters. Although these relationships are determined using (more or less) steady-state values, they suggest that the HR response expressed relative to the individual $H R R$ is a valid measure not only of the relative cardiovascular strain, but also of individual task difficulty and physical strain. The question remains whether a parameter reflecting total strain would be a better indicator of physical strain and task difficulty than the peak strain as measured in the current study. A serious problem preventing the use of a parameter reflecting total strain (such as an integrated HR) is that such a parameter, in contrast to the highest $\mathrm{HR}$, is often too difficult to determine during shortlasting non-steady-state tasks. ${ }^{19}$

\section{Physical strain}

From Table II it will be clear that in general the subjects with higher lesions experience higher levels of strain during all tasks studied. These differences could have been expected since lesion level has an important influence on the amount of muscle mass available for performing activities and hence on the task difficulty. Although the strain appears to be related to the lesion level, the large within-group differences indicate that lesion level is not the only determinant of physical strain.

During some of the tasks physical strain approached or even reached maximum levels in some subjects. This may be even more remarkable when it is considered that tasks were carried out in a well-adjusted standardised setting, with sufficient rest before and after each task and that all tasks were performed as single isolated tasks. In daily life, where the environment is not always adequately adjusted and where various activities are often performed simultaneously or successively without rest, ${ }^{3}$ or where factors such as a high ambient temperature may cause additional stress, ${ }^{21}$ the stress during ADL may be considerably higher than in the laboratory. This can result in a high strain during a certain task in those persons who had low levels of strain in the laboratory and may even result in an impossiblity to perform the same task for those with high levels of strain in the laboratory. The high physical strain among these individuals may not only result in fatigue and discomfort, restricting mobility and independence, but may also cause an 
overload of the cardiorespiratory system in older persons or those with disturbed or weak cardiorespiratory functioning.

Not all subjects were able to perform all tasks. Especially transfers, ascending the curb and entering the car appeared to be too difficult for subjects with a low physical capacity. For the transfer to the bed, the bed height appeared too high for placing the legs onto the bed. In daily life these subjects have fewer problems since they use a high-low bed, enabling them to lower the bed before the transfer, whereas in the present study the bed height was equal to the wheelchair seat height. Six subjects were not able to transfer to a shower wheelchair because no assistive devices could be used and five subjects were not able to ascend the curb. These subjects have to depend on others during daily life for such tasks and are consequently more restricted in their mobility which will limit their social radius of action.

From Figure 1 it will be clear that entering a car is the most burdensome task and even too heavy to perform for many subjects. Surveys have shown that a large part of the wheelchair user population has difficulties entering/leaving a car independently. ${ }^{22.23}$ Since in the present study all subjects used an electric hoist to load the wheelchair, the most important factor causing the strain must have been the transfer from the wheelchair into the car. Reasons for the high physical strain may be the low position of the car seat, a raised sill over which feet must be lifted and the limited horizontal and vertical clearance.

The physical strain during passing a sidehung door and washing hands was as expected lower than in other tasks. Washing hands, in contrast to for example transfers, does not involve heavy muscular exercise nor complex movements. The passing of the door, consisting of opening, passing and closing of a side-hung door, did not provoke high levels of strain in those with paraplegia. The subjects with tetraplegia obviously had more difficulty in manoeuvering through the door and had as a result higher levels of strain ( $40 \pm 14 \%$ HRR $)$.

The physical strain during the curb ascent was not very high among the groups with paraplegia. However, several subjects were not able to make the ascent. Three of the nine subjects with tetraplegia were not able to perform the ascent while the physical strain among those subjects with tetraplegia who made the ascent independently was considerably higher than in the groups with paraplegia. The ramp ascent induced on average a moderate physical strain of $39 \%$ HRR. The large standard deviations, however, indicate that some subjects reached excessive levels of strain which is also found in other studies., ${ }^{2,3}$ This will not only restrict the mobility but may also be hazardous in some cases in which the user is no longer able to control his wheelchair. The levels of strain found in the present study are similar to those found in Janssen et $a l^{3}$ among the same subjects in real life. However, in the latter study, the values represented the mean physical strain whereas in the present study only peak values are given, again indicating that in real life the strain may be considerably higher than in a controlled laboratory situation.

It has often been asserted that making transfers is a very burdensome task for wheelchair users. However, for a large part of the subjects in the present study, making a transfer from a wheelchair to a toilet or a shower seat does not provoke a high strain that may fatigue the individuals. Although the physical strain estimated by the heart rate response is not extremely high for the majority of subjects, intra-articular pressure in the shoulder while transferring has been shown to rise dramatically, ${ }^{24}$ suggesting that the bones, joints, and soft tissues of the upper-body are subjected to considerable stress while supporting the whole body. This stress may account for the high rate of shoulder problems in persons with SCI. ${ }^{24.25}$

Although household activities in this study were relatively light (no vigorous upper-body movements were necessary), the physical strain could be considerably high in some subjects. Especially changing sheets provoked high levels of strain, even significantly higher than the curb ascent or the transfer to the toilet (Fig 1). Household tasks are notably more time-consuming and may therefore be additionally stressful to some individuals. In the present study, the 
bed was easily accessible from all sides. This will not always be the case in the home setting of subjects which may add substantially to the task difficulty.

\section{Relationship between physical capactiy and physical strain}

Parameters for physical capacity were inversely related to lesion level: the subjects with tetraplegia had significantly lower values for all parameters than the groups with the lowest lesions which is in agreement with previous studies. ${ }^{26}$ However, the large within-group variations indicate that differences among subjects within the same lesion level group may be extensive. Other factors such as health problems, activity level, or genetic endowment, may, just as in the able-bodied population, affect physical capacity to an important extent, which may be further affected by the completeness of the lesion.

Physical capacity was inversely related to strain during the tasks, which agrees with cross-sectional studies showing that subjects with SCI with higher physical capacity have a lower physical strain during arm cranking at equal (absolute) work load. ${ }^{8,9,11}$ In general, the correlations between physical capacity and physical strain were notably higher when only data from subjects with complete lesions were used, which may be explained by the fact that the measurements of physical capacity merely reflect upper-body capacity while during the tasks not only the upper body could be used but also (parts of) the lower body. For example, one subject with an incomplete cervical lesion had a low physical (upper-body) capacity, but was able to use his legs to support his body while transferring, reducing the tasks difficulty and consequently disturbing the relationships studied. This suggests that parameters for upper-body capacity may not be sufficient to predict the physical strain in subjects with incomplete lesions, since also the remaining lower-body capacity has to be taken into account.

The correlation coefficients studied may have been disturbed by other factors. Although the tasks were standardized to a certain extent (same temperature, task order, adjustments of assistive devices, and resting periods), the actual work load is, in contrast to submaximal arm cranking or wheelchair propulsion, difficult to determine and even more difficult to impose. Differences in task performance are inevitable. Some subjects will have performed the task more efficiently, with a different velocity, with other assistive devices than others. In addition, anthropometric differences (body mass, arm length etc) undoubtedly have contributed to differences in actual work load. Since all subjects used their own daily-use wheelchair, differences in wheelchair characteristics have induced an additional variation in work load and consequently in physical strain among subjects. Moreover, spastic contractions of the paralysed limbs, which frequently occur in these persons when the position of the lowerlimbs is changed after a long period in one position, such as during transfers, ${ }^{27}$ may have altered the amount of active muscle mass and consequently the physical strain. In spite of these 'disturbing' influences, the relationship between physical capacity and physical strain was obvious, emphasising the importance of physical capacity.

In all regression equations concerning transfers, entering the car, and negotiating ramp and curb, a parameter for physical capacity relative to the individual body mass was entered whereas only absolute parameters appeared in the equations for the household activities, washing hands and passing the door. This may be explained by the fact that during the latter tasks no height differences have to be overcome. During the transfers the whole body has to be lifted and moved and hence every extra body mass evokes an increased work load. This stresses the importance for these individuals to reduce excessive body mass (especially adipose tissue) in order to decrease the work load during these tasks.

The most important predictors of physical strain were POmax and $\dot{\mathrm{VO}} 2$ peak, since they appeared initially in eight and four of the equations, respectively. Although a recent study demonstrated that relationships among $\mathrm{F}_{\text {iso }}, \mathrm{P} 30, \mathrm{VO}_{2}$ peak and POmax were strong in wheelchair users with SCI, ${ }^{16}$ POmax and $\dot{\mathrm{V}} \mathrm{O}_{2}$ peak seem to be the most important determinants of physical strain 
during ADL. In addition to POmax and $\dot{\mathrm{V}} \mathrm{O}_{2}$ peak, $\mathrm{F}_{\text {iso }}$ was entered secondly into five of the 12 equations, indicating that subjects with an equal POmax or $\dot{\mathrm{V}} \mathrm{O}_{2}$ peak but with more isometric strength will have less strain during the transfers and the curb ascent. The isometric component during these tasks can be very high and isometric strength may therefore determine physical strain during these tasks to an important extent. Age was entered in the equations for the transfer to the bed and the ramp ascent, indicating that subjects with an equal physical capacity but a higher age have less strain during these tasks. This might be explained by a decreased heart rate sensitivity to activity with age, resulting in a lower heart rate response. ${ }^{28}$ Another explanation might be that younger subjects performed the tasks more swiftly than older subjects, augmenting the workload and consequently the strain.

Indices of physical capacity appeared to explain more of the variance in physical strain than the level of lesion. This indicates that, although physical capacity is clearly related to level of lesion (Table III), it provides additional information beyond level of lesion alone and seems a more important parameter to predict reactions to stress in persons with SCI.

The question that arises here is whether the proposed relationship between physical capacity and strain during ADL tasks is a causal relationship. In other words, does a change in physical capacity result in an inverse change of physical strain? This question cannot be answered from the results of the present study due to its cross-sectional design. Longitudinal (experimental) research is indispensable to ascertain the causality of the relationship. However, it has been demonstrated that a training regimen can increase the physical capacity of subjects with SCI and reduce in this way the HR response during submaximal wheelchair or arm crank exercise. ${ }^{5.10-12}$ Whether a wheelchair traininginduced increase in physical capacity also results in a reduction in physical strain during other tasks, such as making transfers or household activities, remains to be investigated.
Not only an increase in physical capacity but also a reduction in actual work load could reduce physical strain during ADL. The workload may be reduced through for example improvement of wheelchair mechanics (reducing drag forces ${ }^{29}$ ), through reduction of excessive body and wheelchair mass, and through diminishing the environmental barriers. Moreover, an increased economy of task performance will also reduce physical strain and may be achieved through ergonomically improved assistive devices, including the wheelchair, ${ }^{18}$ and through task training as performed during rehabilitation. In addition, taking a longer time, when possible, may also reduce the physical strain during ADL.

In summary, the method used in this study was shown to be a useful tool in estimating the physical strain during standardised ADL and in comparing physical strain among subjects with SCI. It was demonstrated that: (1) the physical strain of ADL could be notably high, but that large variations among subjects were present indicating that some subjects have very high levels of strain whereas others have low levels of strain during the same task; (2) subjects with high lesions had in general higher levels of physical strain during all tasks studied; (3) physical capacity was inversely related with physical strain during all tasks and appeared to be more important than the level of lesion in explaining the variance in physical strain.

\section{Acknowledgements}

This study was supported by grants from Linido BV, Pijnacker, The Netherlands, and from StiPT Executive Agency for Technology Policy, The Netherlands, and was carried out in joint cooperation with the Department of Exercise Physiology and Biophysics (T W J Janssen, A P Hollander), the Department of Health Science (C A J M van Oers, L H V van der Woude) and the Department of Functional Anatomy (H E J Veeger, R H Rozendal). Thanks are due to B\&S Autoaanpassing BV, Hoorn, The Netherlands for the electric hoist and to Remploy, UK, for placing their Autobility System at our proposal; to Pronk Ergo BV, Zoetermeer, The Netherlands, for the wheelchair-accessible kitchen, to Stabag PcP BV, Oudenbosch, The 
Netherlands, for the $8 \mathrm{~m}$ ramp, and to Oostwoud International BV, Veenendaal, The Netherlands, for the height-adjustable bed. The authors gratefully acknowledge the involvement of L M van Berkel, A J Dallmeijer, F G de Haan, B E Houtzager, Y J Kappe, W Rasche, H J M Vandenboorn, T Visser, and H Yzelenberg in the data collection.

\section{References}

1 Hoffman MD (1986) Cardiorespiratory fitness and training in quadriplegics and paraplegics. Sports Med 3: 312-330.

2 Hjeltnes N, Vokac Z (1979) Circulatory strain in everyday life of paraplegics. Scand J Rehabil Med 11: 67-73.

3 Janssen TWJ, Oers CAJM van, Woude LHV van der, Hollander AP (1994) Physical strain in daily life of wheelchair users with spinal cord injuries. Med Sci Sports Exerc 26: 661-670.

4 Cerny K, Waters R, Hislop H, Perry J (1980) Walking and wheelchair energetics in persons with paraplegia. Phys Ther 60: 1133-1139.

5 Glaser RM, Sawka MN, Durbin RJ, Foley DM, Suryaprasad AG (1981) Exercise program for wheelchair activity. Am J Phys Med 60: 67-75.

6 Ilmarinen J (1984) Physical load on the cardiovascular system in different work tasks. Scand J Work Environ Health 10: 403-408.

7 Nygård C-H, Suurnäkki T, Ilmarinen J (1988) Effects of musculoskeletal work load and muscle strength on strain at work in women and men aged 44 to 58 years. Eur J Appl Physiol 58: 13-19.

8 Zwiren LD, Bar-Or O (1975) Responses to exercise of paraplegics who differ in conditioning level. Med Sci Sports 7: 94-98.

9 Davis GM, Shephard RJ (1988) Cardiorespiratory fitness in highly active versus inactive paraplegics. Arch Phys Med Rehabil 67: 463-468.

10 DiCarlo SE (1988) Effect of arm ergometry training on wheelchair propulsion endurance of individuals with quadriplegia. Phys Ther 62: 456-459.

11 Sedlock DA, Knowlton RG, Fitzgerald PI (1988) The effects of arm crank training on the physiological responses to submaximal wheelchair ergometry. Eur J Appl Physiol 57: 55-59.

12 Whiting RB, Dreisinger TE, Dalton RB, Londeree BR (1983) Improved physical fitness and work capacity in quadriplegics by wheelchair exercise. J Cardiac Rehabil 3: 251-255.

13 Hildebrandt G, Berendes B, Kroeger J (1970) Energy costs of propelling a wheelchair at various speeds: cardiac response and effect of steering accuracy. Arch Phys Med Rehabil 51: 131-136.

14 Wolfe GA, Waters R, Hislop HJ (1977) Influence of floor surface on the energy cost of ambulation in spinal cord injury. Phys Ther 57: 1022-1027.

15 Dutch Council of Disabled (1989) Geboden Toegang. Stichting Nederlandse Gehandicaptenraad, Utrecht: 54 (in Dutch).

16 Janssen TWJ, Oers CAJM van, Hollander AP, Veeger HEJ, Woude LHV van der (1993) Isometric strength, sprint power, and aerobic power in individuals with a spinal cord injury. Med Sci Sports Exerc 25: $863-870$.

17 Niesing R, Eijskoot F, Kranse R, Den Ouden AH, Storm J, Veeger HEJ, Woude LHV van der, Snijders CJ (1990) A computer controlled wheelchair ergometer. Med Biol Eng Comp 28: 329-338.

18 Woude LHV van der, Ingen Schenau GJ van, Rozendal RH, Hollander AP (1986) Wheelchair ergonomics and physiological testing of prototypes. Ergonomics 29: 1561-1573.

19 Janssen TWJ, Oers CAJM van, Woude LHV van der, Hollander AP (1994) Reliability of heart rate responses to non-steady-state activities of daily living in men with spinal cord injuries. Scand J Rehabil Med 26: $71-78$.

20 Karvonen J, Chwalbinska-Moneta J, Saynajakangas S (1984) Comparison of heart rates measured by ECG and microcomputer. Phys Sports Med 12: 65-69.

21 Gertner A, Israeli R, Cassuto Y (1984) Effects of work and motivation on the heart rates of chronic heat-exposed workers during their regular work shifts. Ergonomics 27: 135-146.

22 Mitchell CGB (1986) Problems experienced by disabled and elderly people entering and leaving cars. In: Kiippers H-J, editor. The Adaptation of Cars for Paralysed Persons. COMAC BME, Edizioni Pro Juventute, Milano: 27-29.

23 Roebroeck ME, Rozendal RH, Woude LHV van der (1988) Telephone questionnaire. In: Roebroeck ME, Woude LHV van der, Rozendal RH, editors. Methodology of Consumer Evaluation of Hand Propelled Wheelchairs. COMAC-BME, Edizoni Pro Juventute, Milano: 23-45.

24 Bayley JC, Cochran TP, Sledge CB (1987) The weight-bearing shoulder. J Bone Joint Surg 69-A(5): 676-678.

25 Gellman H, Sie I, Waters RL (1988) Late complications of the weight-bearing upper extremity in the paraplegic patient. Clin Orthop Rel Res 233: 132-135.

26 Burkett LN, Chisum J, Stone W, Fernhall B (1990) Exercise capacity of untrained spinal cord injured individuals and the relationship of peak oxygen uptake to level of injury. Paraplegia 28: 512-521. 
27 Little JW, Micklesen P, Umlauf R, Britell C (1989) Lower extremity manifestations of spasticity in chronic spinal cord injury. Am J Phys Med Rehabil 68: 32-36.

28 Lakatta EG (1993) Cardiovascular regulatory mechanisms in advanced age. Physiol Rev 73: 413-467.

29 Frank TG, Abel EW (1993) Drag forces in wheelchairs. In: Woude LHV van der et al, editors. Ergonomics of Wheelchair Propulsion: State of the Art. COMAC-BME, Edizioni Pro Juventute, Milano, IOS Press, Amsterdam: 255-267. 